\title{
ADHD and Present Hedonism: time perspective as a potential diagnostic and therapeutic tool
}

This article was published in the following Dove Press journal:

Neuropsychiatric Disease and Treatment

16 November 2016

Number of times this article has been viewed

\author{
S Weissenberger' \\ M Klicperova-Baker ${ }^{2}$ \\ P Zimbardo ${ }^{3}$ \\ K Schonova' \\ D Akotia' \\ J Kostal ${ }^{2}$ \\ M Goetz ${ }^{4}$ \\ J Raboch' \\ R Ptacek'
}

'First Medical Faculty, Charles University, ${ }^{2}$ Institute of Psychology, Academy of Sciences of the Czech Republic, Praha, Czech Republic; ${ }^{3}$ Department of Psychology, Stanford University, Stanford, CA, USA; ${ }^{4}$ Second Faculty of Medicine, Department of Child Psychiatry, Charles University, Motol University Hospital, Praha, Czech Republic
Correspondence: R Ptacek

First Medical Faculty, Charles University, Katerinska 1660/32, 12I 08 Praha 2.

Czech Republic

Email ptacek@neuro.cz
Abstract: The article draws primarily from the behavioral findings (mainly psychiatric and psychological observations) and points out the important relationships between attention-deficit/ hyperactivity disorder (ADHD) symptoms and time orientation. Specifically, the authors argue that there is a significant overlap between the symptoms of ADHD and Present Hedonism. Present Hedonism is defined by Zimbardo's time perspective theory and assessed by Zimbardo Time Perspective Inventory. Developmental data on Present Hedonism of males and females in the Czech population sample $(\mathrm{N}=2201)$ are also presented. The hypothesis of relationship between ADHD and Present Hedonism is mainly derived from the prevalence of addictive behavior (mainly excessive Internet use, alcohol abuse, craving for sweets, fatty foods, and fast foods), deficits in social learning, and increased aggressiveness both in ADHD and in the population scoring high on Present Hedonism in the Zimbardo Time Perspective Inventory. We conclude that Zimbardo's time perspective offers both: 1) a potential diagnostic tool - the Zimbardo Time Perspective Inventory, particularly its Present Hedonism scale, and 2) a promising preventive and/or therapeutic approach by the Time Perspective Therapy. Time Perspective Therapy has so far been used mainly to treat past negative trauma (most notably, posttraumatic stress disorder); however, it also has value as a potential therapeutic tool for possible behavioral compensation of ADHD.

Keywords: ADHD, time perspective, ZTPI, Zimbardo, addiction, alcoholism, delinquency, video games, problematic Internet use

\section{Introduction}

Attention-deficit/hyperactivity disorder (ADHD) is a widespread neurodevelopmental disorder, the prevalence and significance of which is rapidly growing. Increasing numbers of people suffer from the ADHD syndrome. The symptoms include a wide array of manifestations and experiences. In modern times, the ever-increasing life's tempo, ever-growing stress, and last but not least, the onset of the ubiquitous electronic technology environment also tend to exacerbate ADHD. The connection between ADHD and time perception specifically using the methods laid out by Zimbardo and Sword and the Zimbardo Time Perception Inventory can bring a new and helpful tool in diagnosis and therapy of ADHD., ${ }^{1,2}$

\section{The incidence, characteristics, comorbidities, and categories of ADHD}

ADHD is a disorder which is widely known and classically recognized in children but that is only recently getting studied in the adult population. ${ }^{3}$ Simon et al report that prevalence of adult ADHD is $2 \%-3 \%{ }^{3}$ Other sources state that ADHD affects between $5 \%{ }^{4}$ and $11 \%{ }^{5}$ of the population aged $4-17$ years in the US. Fayyad et al report that the prevalence of ADHD is around 5.3\% in the pediatric population and 
$3.4 \%$ in the adult population. ${ }^{6}$ However, recent data suggest even more dramatic occurrence of ADHD: "almost 1 in 5 teenage boys and $11 \%$ of all school-aged children have been diagnosed with ADHD". ${ }^{7}$ ADHD is a neurodevelopmental disorder. However, rather than by its neurological substance and causes, it tends to be described by observable behavioral manifestations. The marked symptoms of ADHD include general inattention, hyperactivity, impulsivity, and difficulty with self-control.

ADHD used to be classified as a childhood syndrome, but it has recently become a chronic, lifelong disorder with "ADHD", "childhood ADHD", and "adult ADHD" defined as three different categories under Diagnostic and Statistical Manual of Mental Disorders, fifth edition (DSM-V). In the DSM system, the child or teenager can be labeled with the diagnosis of "predominantly inattentive", "predominantly hyperactive impulsive", or a mix of the two categories (DSM); the symptoms can later be carried on to adulthood. Failure to observe a linear progression from childhood to adult ADHD leads many to believe that with time, there is a "catch up" in development and the symptoms may remit into adulthood. ${ }^{8}$ The variety of causes and triggers is emphasized by the fact that the disorder can be managed to some extent by drug therapy and/or psychotherapy. ${ }^{9}$

The literature is abound with reports on the neurological and hormonal peculiarities of children with ADHD. ${ }^{10-12}$ Furthermore, neuroimaging studies have shown developmental differences in children with ADHD, especially disparity in the maturation of the cortex and the cerebellum. ${ }^{13,14}$ Children and adults with ADHD also seem to differ from non-ADHD individuals in that various deficiencies in the striatum have been observed. This is specifically related to the dopaminergic system, the reward system and dopamine. ${ }^{15}$ Dopamine is directly related to reward-seeking behavior, impulsivity, and addictions. However, to what degree dopamine-serotonin interactions are at the source of ADHD still remains a continuing debate. ${ }^{16,17}$

ADHD was also found to have a genetic component. ${ }^{18,19}$ Specific genetic differences have been reported which link ADHD, impulsive behavior, delinquency, and also hedonism. ${ }^{20}$ It is also hypothesized that ADHD may be connected with specific changes in physical growth. ${ }^{21,22}$

There is no single clinical picture of ADHD. There are marked differences between the impulsive and inattentive types that have been isolated and described. ${ }^{23}$ Although both the inattentive and hyperactive subtypes share the same diagnostic definition, they often manifest very different symptoms and comorbidities. According to Grizenko et al, the two subtypes appear as almost separate diagnoses. ${ }^{24}$ While looking at comorbidities, these authors found that the hyperactive group displayed symptoms such as conduct disorder, while the inattentive group manifested different ones (mainly depression). Another example of a difference in comorbidities is that the inattentive group often shows comorbid obesity, whereas the hyperactive group does not. ${ }^{25}$ Other comorbidities associated with the hyperactive/impulsive subtypes are drug abuse and addictive behavior. ${ }^{26}$

\section{Correspondence in lifestyles of ADHD and Present Hedonistic individuals}

The literature from various sources (neurological, genetic, and behavioral disciplines) seems to concur that there is a close link between ADHD and present-oriented behavioral patterns both in children and adults. This present-oriented behavior includes a wide array of behaviors which are hedonistically oriented: alcohol and drug abuse, compulsive gambling, dependence on electronic media, poor eating habits, higher rates of obesity and overall body weight in people, nicotinism, and others. ${ }^{27,28}$

Analyses of populations of "alcohol abusers and alcoholics" indicate that up to $71 \%$ of the population have ADHD and in the case of other drug abusers, the number is up to $25 \% .^{29,30}$ Similarly, predominantly present hedonistically minded individuals were found to suffer from higher rates of drug and alcohol abuse. ${ }^{31}$ Interestingly, one genetic expression - the dopamine receptor genes (DRD2, DRD4) associated with ADHD and impulsivity ${ }^{32}$ - was also associated with alcoholism..$^{33}$ In a prospective study, higher rates of alcohol consumption were found among Present Hedonistic and Past Negative individuals. ${ }^{34}$ Impulsive drinking and drug abuse were directly correlated with ADHD diagnosis in various studies. ${ }^{35,36}$ Individuals with a diagnosis of childhood ADHD and conduct disorder were found to be at much higher risk than controls for becoming "drug abusers" in adolescence. ${ }^{37}$

Patients suffering from ADHD as well as Present Hedonists often manifest very "poor dietary choices". These include high consumption and often dependence on fatty foods, sweets, and fast food. ${ }^{38}$ A prospective study carried out in Australia on 2868 children found a correlation between ADHD and a "Western" type diet that included fast food; this was compared with a "healthy" diet that included adequate amounts of fruits and vegetables. Howard et al noted that impulsive eating can also become an addictive behavioral pattern ${ }^{39}$ often seen in ADHD. ${ }^{22}$ One major predictor of binge eating in adolescence was found to be childhood ADHD. ${ }^{40}$ Furthermore, a study by Wilhelm et al analyzed the difference between overweight 
and ADHD individuals and found more impulsiveness within the ADHD group, especially at the beginning of the meal. ${ }^{41}$ Binge eating itself may be addictive or it is conjointly linked with other addictions, nutritional or behavioral. ${ }^{24} \mathrm{~A}$ high correlation between binge eating/food addiction and cocaine abuse has been found, specifically for high fatty food intake. ${ }^{42}$ Swanson et $\mathrm{al}^{43}$ and $\mathrm{Nigg}^{26}$ attest that both binge eating and bulimia nervosa are connected with ADHD, and the common comorbidity of eating disorders in adolescence is substance abuse. A great amount of research has been done on ADHD and dietary habits, whereas the literature on Present Hedonism and lifestyle is just starting to emerge.

Current information technology has led to a whole new area of addictions. Most generally, they are labeled as problematic Internet use (PIU). PIU has been a topic of interest in psychiatric and clinical settings since the late $90 \mathrm{~s}$; this diagnosis had been proposed, but was later rejected by the DSM. The impulsive and addictive use of the Internet has been deemed problematic for certain individuals and indeed clinically significant. The disorder met all the criteria for being identified as an impulse control disorder, which is marked by impulsive behavior. ${ }^{44}$

ADHD is often associated with PIU. ${ }^{45} \mathrm{~A}$ correlation was found between PIU and alcohol abuse/dependence among adolescent populations in Germany and Korea. ${ }^{46}$ Although Internet use can well serve educational and recreational purposes, increasing evidence shows its excessive and addictive abuse. The incidence of PIU has been estimated at 2\%-20\% among young people and has been increasing. ${ }^{47}$ Zimbardo and Coloumbe highlight a wide range of negative consequences among boys and young men from excessive, socially isolated video gaming coupled with Internet pornography viewing. ${ }^{48}$

In a Korean study, ADHD and depression turned out to be the biggest risk factors for developing online gaming addictions. ${ }^{49}$ In a Turkish study, individuals with ADHD were also more likely to use the Internet impulsively. ${ }^{50}$ Both Chinese and Korean research on Internet addiction among adolescents found boys to be more likely to suffer from the condition than girls; risk factors for developing such dependence were ADHD and impulsivity. ${ }^{51,52}$ This is congruent with the previous studies on the classical forms of addictions (ie, alcohol and other drugs). One possible shortcoming of the study was that there was no distinction between the subtypes of ADHD. The authors of the study did not attempt to discover the differences between the ADHD and depressed groups to see what the reasons for impulsive gaming were (such as for lowering depression or quenching the impulsivity).
An American cross-sectional study on nearly 70,000 children has indicated the "protective factors" against ADHD, which are: watching less than 1 hour of television/gaming a day, being active in sports teams, and a solid family structure. ${ }^{53}$ The unhealthy lifestyles learned from parents, especially from lower socioeconomic status households, should not be underestimated when looking at ADHD and impulsiveness. It is very likely that the impulsive behaviors such as PIU and excessive gaming are directly related to parenting styles and also inadequate care by school teachers.

"Deficits in social learning" as a direct effect of "parenting styles" seem to play a very significant role in development of late-onset ADHD. High emotional expression in parenting (particularly negative-reactive instead of positive parenting strategies) was associated with $\mathrm{ADHD}^{54}$ as well as higher rates of aggressive behavior, fighting, and later impulsivity. ${ }^{55}$ Similarly, research has found a direct correlation with the behaviors and parenting roles in time perspective studies. Specifically, when teenagers perceived their parents as psychologically controlling, the result was that they displayed predominantly Present Hedonistic behaviors. On the other hand, future-oriented teenagers perceived their parents as adequately responsive and giving ample autonomy. ${ }^{56}$ Worrel et al reported the Present Hedonistic mindset to be closely associated with authoritarian and permissive parenting. ${ }^{57}$ Furthermore, authoritarian parenting styles were correlated with disorders such as anxiety ${ }^{58}$ and drug abuse/addiction. ${ }^{59}$ Incidentally, both are major, well-documented comorbidities associated with ADHD. ${ }^{60,61}$ However, deeper analysis of these phenomena is methodologically challenging. Correlational studies tend to describe the vicious circle within the family instead of providing a deeper insight into the causality. In contrast to authoritarian and permissive parenting styles, authoritarian parenting, which is associated with clear roles and boundaries as well as healthy levels of communication, was found to have positive effects. Authoritative parenting styles were found to be the most advisable in managing ADHD in family setting. Maintaining the communication and clear borders were also found to be essential along with medication in managing the symptoms and having healthy family relationships among those suffering from ADHD. ${ }^{62}$

Parenting styles, besides neurological and genetic disorders, are often related to "aggressiveness" among ADHD patients as well as among present-oriented hedonists. In a 2016 study, Stolarski et al administered the Zimbardo Time Perspective Inventory (ZTPI) as well as the Aggression Questionnaire to 300 individuals and found that individuals with Present Hedonistic perspective were more likely to show aggressive and impulsive tendencies. ${ }^{63}$ The study did 
not assess for ADHD symptoms, but it would most likely yield similar results with ADHD being linked to both Present Hedonism and aggression. Likewise, during a neurological mapping study, adolescents with ADHD have been observed to show low inhibition along with high levels of aggression and impulsivity. The study included 18 ADHD diagnosed children and 18 controls, individuals from both groups had their brains scanned by fMRI machines while playing a game specifically designed to elicit aggressive responses to fictitious opponents. The ADHD group displayed significantly more aggressive responses. The comorbidities in the ADHD group included disruptive behavior disorder and conduct disorder. ${ }^{64}$ The study did not inquire about drug usage or any other lifestyle habits of the participants. Again, there was no differentiation between hyperactive impulsive individuals and generally inattentive subjects in this study. We can assume from the comorbidities and aggressiveness that this was most likely the hyperactive/impulsive group that we are associating with Present Hedonism.

Generally, the respective behaviors tend to be related. Both in ADHD and in Present Hedonists, overconsumption of fast food, alcohol as well as unhealthy media habits and Internet use are not only signs of possible disorders but of poor discipline and inadequate parenting. Impulsivity and hedonism are often tied together by various behavioral addictions (ie, gambling, video games, nicotine). Presently, we see new forms of addictions emerge, which both the ADHD group as well as Present Hedonists are likely to suffer from.

\section{Zimbardo time perspective}

Zimbardo developed a time perspective theory with a corresponding standardized questionnaire known as the ZTPI. In this, subjects answer how much of their thoughts are spent in the past, present, and future and whether their time perspective tends to have a positive or negative accent. ZTPI provides five dimensions which are as follows. Past Positive dimension relates to positive reminiscence, for example, certain stimuli bring forward pleasant memories of the past. Past Negative dimension assesses the degree to which unpleasant and possibly traumatic past experiences are influencing the current life of the individual. Present Hedonism focuses on living in the moment, seeking thrill and pleasure. Present Fatalism expresses conviction that rather than by free will, individual lives are influenced by unexpected and uncontrollable forces, fate, luck, and so on. Future dimension assesses to what degree individuals are goal oriented, focusing on accomplishments and responsibilities to other people, and display what is known as a traditional Protestant work ethic. ${ }^{30}$ These dimensions can be assessed individually or in their mutual relationship and balance. Various types of disorders can be attributed to imbalances of time perspective. Examples include anxiety or posttraumatic stress when Past Negative orientation takes over, or risky behaviors and risk-taking in Present Hedonistic orientation. ${ }^{31}$

\section{ADHD and Present Hedonism}

From the above-mentioned literature review of risky lifestyle habits and ADHD comorbidities, we hypothesize a clear and definite correlation between ADHD and Present Hedonistic time orientation. We hypothesize that ADHD sufferers, especially from the hyperactive impulsive subtype, are most likely to be overwhelmingly anchored in the Present Hedonistic mindset. They will more likely engage in behaviors representative of Present Hedonistic time perspective which often leads to substance abuse, poor eating habits, and currently most popular modern addictions, especially PIU, and overall dependence on the electronic media.

As follows from the Zimbardo theory, people with a prevalence of Present Hedonistic orientation are generally very focused on enjoying the present, feeling excited in their lives, and are therefore driven by what Freud called the pleasure principle. Although healthy and well-adapted individuals may enjoy the present moments as well, the Present Hedonism in their case tends to be balanced with a realistic level of future orientation and reminiscence of the past. If Present Hedonism becomes the guiding principle, individuals may be more likely to engage in risky behaviors in order to seek strong sensations; this can possibly put the person at risk of developing addictions, whether classical (ie, alcoholism, overeating, nicotinism) or the newer, electronic versions, such as gaming or Internet addiction. ${ }^{65,48}$

High levels of Present Hedonistic orientation are usual, especially among young males. Empirical data show that Present Hedonism sharply declines with age and it is lower in women. These phenomena are illustrated by the Present Hedonism ZTPI scores of a national survey which we conducted in the Czech Republic. The target population included Czech-speaking residents, almost exclusively Czechs, seldom Slovaks, and rarely other nationalities. The fieldwork was executed by the Sociological Institute of the Czech Academy of Sciences (Center for Public Opinion Research). The sample involved $\mathrm{N}=2,201$ respondents, consisting of $48.8 \%$ males and 51.2\% females, aged 15-89 years (44 years on average). The sample was proportional to the population 


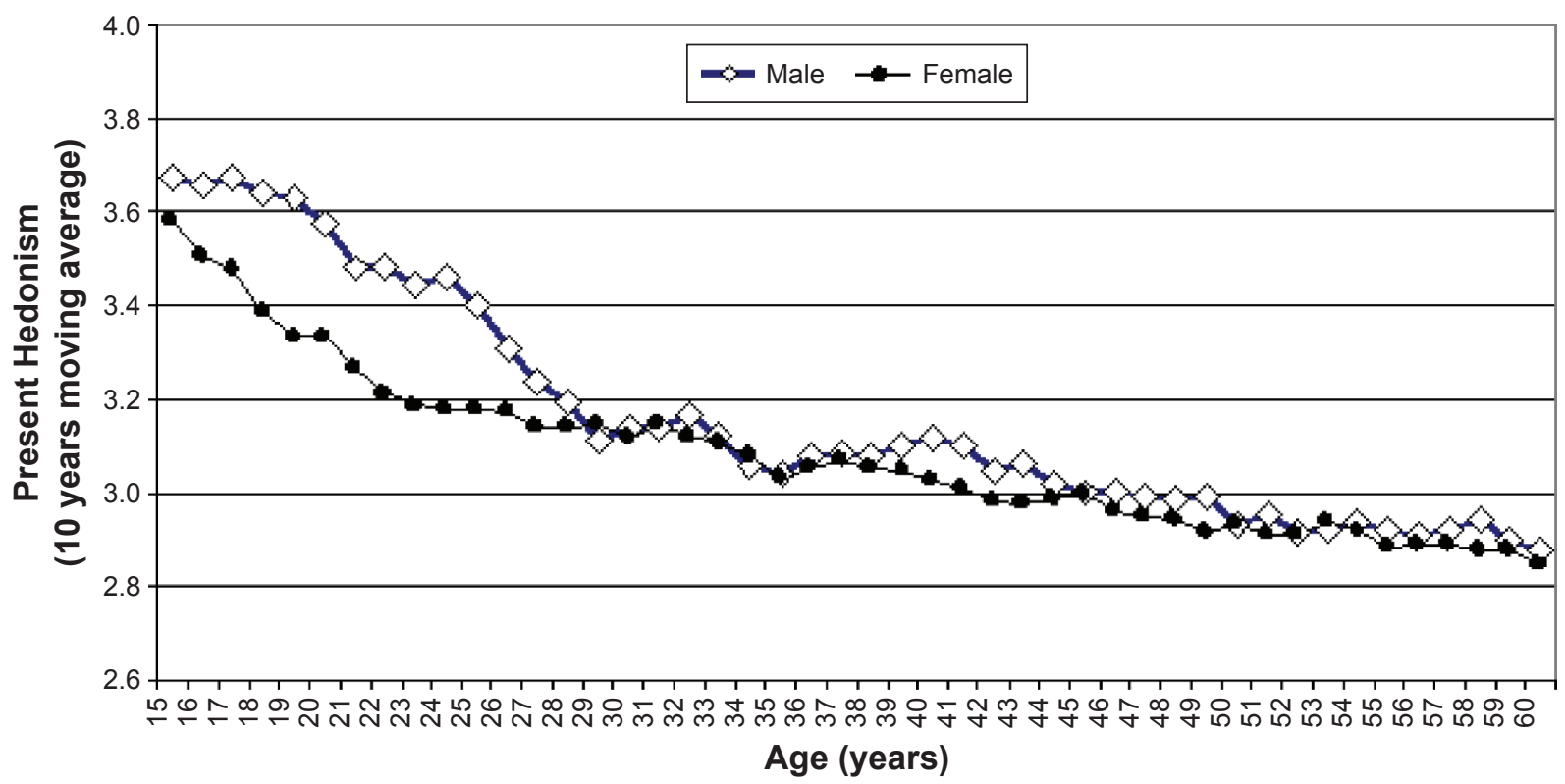

Figure I ZTPI Present Hedonism moving average score: gender difference and the overall decline with age. Values of respondents $>60$ years of age were excluded due to low frequency counts.

Abbreviation: ZTPI, Zimbardo Time Perspective Inventory.

regions and urban-rural areas of the country. The ZTPI data were collected by face-to-face (pen and paper) interview using quota-sampling methodology in two subsequent waves in 2003 and 2008. The relationship between age and the Hedonism scale was calculated from $n=2,118$ valid responses to the Hedonism scale (ie, $96.2 \%$ of the total sample); almost all $(n=2,199)$ respondents were included in the latent class analysis (LCA). This study focused on ZTPI and its 56 items and did not include any ADHD indices at that point.

The overall decline with age was statistically significant (high Eta 0.367 for interval and Cramer's V $=0.248$ for categorized age: Beta $=-208$ in multivariate regression). There were significant differences among all age groups, except the middle-age category of 35-44 years; in the age group of 35-44 years, the decline in Present Hedonism was not apparent.

The gender difference proved significant as well. Higher Present Hedonism in men was confirmed by two-tailed non parametric statistics: both median and Kolmogorov-Smirnov test of independent samples confirmed the difference on asymptotic significance level of 0.023 and 0.008 , respectively. The results are illustrated in Figure 1.

LCA used on the same Czech sample yielded an even more dramatic depiction of the decline of Present Hedonism with age. LCA is able to identify subgroups of really existing respondents of ZTPI who share similar patterns of time perspective. The distinctly Present Hedonistic pattern/class characterized $28 \%$ of respondents. The age composition of this pattern/class is interesting: half of this group was represented by the youngest respondents aged 15-24 years; older ages contributed to this group with radically declining frequency. Figure 2 shows the percentage of respondents from various age categories who constituted a latent class of Present Hedonists.

Men predominated in the Present Hedonists LCA class, as it consisted of $60 \%$ men and only $40 \%$ women. This corresponds to the gender difference observed in Present Hedonism illustrated in Figure 1 and in other studies that find men more Present Hedonistic than women.

As mentioned earlier, ADHD symptoms, as well as Present Hedonism, are also most pronounced in the young age group. ${ }^{66}$ Likewise, gender is a major variable to take into account for addictions, as males are more likely to show addictive behavior such as alcoholism. For example, 58\% of men reported binge drinking on a monthly basis. ${ }^{5}$ Binge drinking is an example of a Present Hedonistic behavior.

\section{Time perspective paradigm as a potential diagnostic and therapeutic tool}

Our article introduces both indicators and pieces of evidence showing that there is a substantial overlap between ADHD and Present Hedonistic orientation. This leads us to hypothesize that Present Hedonism itself in all its various forms may well serve as a telling indicator of ADHD or proneness to ADHD. Furthermore, psychometric methods devised for 


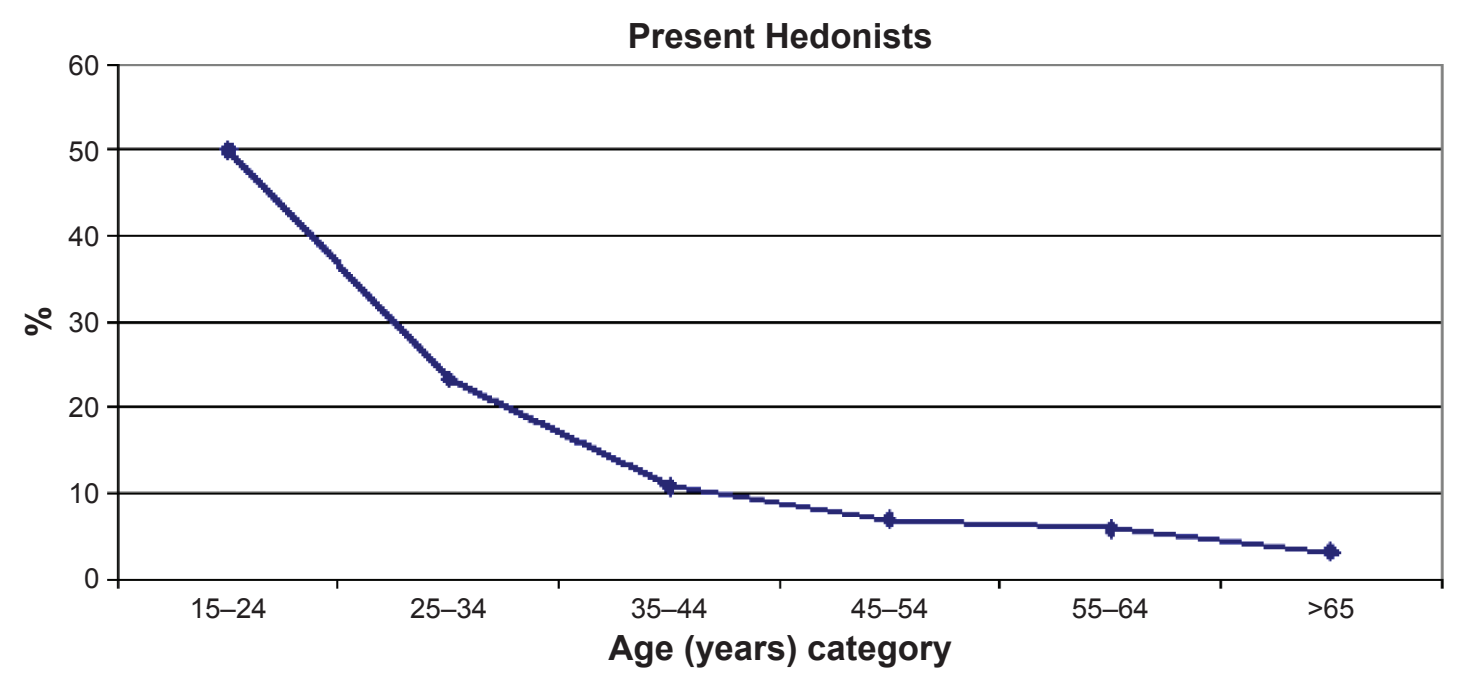

Figure 2 Percentage of respondents of various age categories constituting a class defined by Present Hedonism.

assessment of Present Hedonism, such as ZTPI by Zimbardo, may prove particularly useful for this purpose.

Even more importantly, Zimbardo's temporal theory was elaborated into a systematic therapeutic approach - Time Perspective Therapy (TPT). So far, this approach has been used mainly to treat clients who are pathologically focused on their Past Negative experiences due to their traumatic past. These include especially war veterans who suffer from posttraumatic stress disorder, but also include survivors of abuse, accidents, assault, and neglect. In their case, TPT is being used to restore the temporal balance, to switch negativity to positivity, and to shift from the past to present and to future. Zimbardo et $\mathrm{al}^{2}$ provide a detailed description of the procedure in The Time Cure: Overcoming PTSD with the New Psychology of Time Perspective Therapy, which is praised as a "landmark book". Similar time perspective principles that take into account the ratio of the past, present, and future have been traditionally used in gerontology and geriatrics. ${ }^{67,68}$ Similarly, patients suffering from depression and dwelling in negative past may profit from reframing their time perspective, which is an observation by Bitsko et al who worked with depressive adolescent cancer patients. ${ }^{69}$

In contrast to the above-mentioned groups, most of which consist of patients "stuck to the past", the ADHD patients seem to suffer from being "stuck in the present". Coincidentally, this is the core of the title that Gruber et al used for their article about mania and its association with the present oriented time perspective. ${ }^{70}$ Refugees are another group of clients who have been known to "focus on the present to the relative exclusion of past and future" 71 or to suffer from "atomism" of a single time orientation. ${ }^{72}$ Also, prisoners may suffer from a similar exclusive focus. ${ }^{73}$
And then, of course, intense orientation in the present time has been observed in a wide array of people who suffer from dependencies that are very often linked to ADHD and that have been described above. Only sporadic reports mention the usefulness of time perspective as a useful framework or even as a possible direction of treatment. For example, Henik and Domino published an article entitled, "alterations in future time perspective in heroin addicts."74 "Excessive players" and pathological gamblers' time perspective and the possible therapeutic uses thereof are mentioned in the reports of Hodgins and Engel ${ }^{75}$ and Lukavska. ${ }^{76}$ Finally, irrespective of diagnoses, Stolarski et a ${ }^{63}$ point out the significance of balanced time perspective for a general satisfaction with life.

Overall, it is surprising that although ADHD tends to be viewed as a disorder which generally responds well to behavioral therapy, ${ }^{77}$ TPT in general - or, specifically, the TPT approach by Zimbardo and Sword ${ }^{2}-$ is not discussed and utilized more. We hope that this article will help to correct this blind spot.

\section{Discussion}

This article reviews significant relationships between ADHD and various factors - from genetic and neurological to developmental and social. Attention is also paid to a range of manifestations of typical ADHD lifestyle and comorbidities. It is concluded that Zimbardo's time perspective approach suggests an important relationship between ADHD and Present Hedonism.

Although literature is available both on ADHD and, to a lesser degree, on time perspective, many of the studies are methodologically limited. Many are based mostly on correlations, without a deeper concern for the direction of 
causality. Furthermore, the ADHD studies typically do not differentiate between the two main types of ADHD disorder. Although our focus is mostly on the hyperactive subtype of ADHD, the differentiation between inattentive and hyperactive is not always properly recorded by clinicians and, as such, can create some confusion in the findings.

Some studies arrived at counterintuitive results. Carelli and Wiberg compared 30 ADHD participants and 30 controls in a Swedish study and found that ADHD was associated with predominantly future positive time perspective. ${ }^{78}$ However, a major confounding factor was that the patients were already being pharmacologically treated for ADHD. Perhaps, they had measured the effects of treatment rather than ADHD itself.

In any case, our hypothesis is that ADHD individuals seem to live in a different time perspective than the general population. In Principles of Psychology, William James argued that time is a sensation. ${ }^{79}$ It appears that ADHD individuals spend their waking state (possibly dream states as well) more often in Present Hedonism than other individuals to the detriment of their future. The modern era poses a particular challenge for ADHD-prone individuals by the new electronic environment that is both widespread and intensive.

At the same time, it is pointed out that modern psychology, namely, Zimbardo's time perspective theory, provides a new paradigm which is useful as a new insight into the substance of ADHD, the methodology of assessment of proneness to ADHD, and finally, the possible therapeutic interventions based on the concept of balanced time perspective. It is surprising that all of the relevant literature only seldom mentions about the therapeutic use of time perspective. We hope this article will contribute to the eventual implementation of temporal interventions in therapy. Still, we realize that although the relationship between ADHD and excessive focus on Present Hedonism seems to be straightforward, the relationship itself and the therapeutic interventions may not be that simple. Let us take an example from Lukavska. ${ }^{76}$ She found in her study of online game players among others that "present fatalistic TP [time perspective] was demonstrated to be a stronger predictor of extensive playing than present hedonistic TP". Such finding calls for replacing of simple correlational studies by more complex models which take into account mediating roles of multiple variables.

The stressors leading to ADHD are increasing, along with the enticing incentives of the brave new electronic world (even electronic schools) and with fast food, cigarette, pornography, and other industries. These industries are particularly focused on targeting ever-younger consumers. ${ }^{80}$
The instant gratification principle is facilitated by advertising to young people, appealing to adults not to deprive their loved ones, seducing young consumers by credit cards, and so on. The peer pressure is increased by use of electronic social media such as Facebook and others.

All this poses a grave threat to the public health not just in the developed countries but also in the developing countries. Thus, while ADHD is one of the most diagnosed disorders, it is also one of the most misdiagnosed disorders. After all, the ADHD lifestyle may often be just a symptom of novelty seeking, an expression of conforming social mimicry, or a defense mechanism to the overstimulated electronic state of consciousness in children and young adults. The search for new effective approaches to assessment and treatment of ADHD in the current era is particularly topical. Zimbardo's time perspective perception approach seems to provide both a welcome theoretical basis as well as a practical tool. It becomes not only a medical and educational issue, but also a philosophical question as to how to utilize the current technology and at the same time promote sanity, harmony, and freedom, both individual and collective.

\section{Acknowledgments}

Klicperova-Baker and Kostal were supported by RVO 68081740 and by a grant \#15-11062S by the Grant Agency of the Czech Republic. This work was supported by the grant Prvouk Psychologie UK. The authors wish to thank the Sociological Institute of the Czech Academy of Sciences (Center for Public Opinion Research - CVVM) and Dr Jiří Vinopal for their support to this study.

\section{Disclosure}

The authors report no conflicts of interest in this work.

\section{References}

1. Zimbardo PG, Boyd JN. Putting time in perspective: a new individual differences metric. J Pers Soc Psychol. 1999.

2. Zimbardo P, Sword R, Sword R. The Time Cure: Overcoming PTSD with the New Psychology of Time Perspective Therapy. San Francisco: John Wiley \& Sons; 2012.

3. Simon V, Czobor P, Bálint S, Mészáros A, Bitter I. Prevalence and correlates of adult attention-deficit hyperactivity disorder: meta-analysis. Br J Psychiatry. 2009;194(3):204-211.

4. Association AP. Diagnostic and Statistical Manual of Mental Disorders $\left(D S M-5^{\circledR}\right)$. Washington: American Psychiatric Pub; 2013.

5. Cuffe SP, Visser SN, Holbrook JR, et al. Attention-deficit/hyperactivity disorder and psychiatric comorbidity: functional outcomes in a schoolbased sample of children. J Atten Dis. Epub 25 Nov 2015.

6. Fayyad J, De Graaf R, Kessler R, et al. Cross-national prevalence and correlates of adult attention-deficit hyperactivity disorder. Br J Psychiatry. 2007;190(5):402-409.

7. Schwarz A, Cohen S. A.D.H.D. seen in $11 \%$ of U.S. children as diagnoses rise. New York Times. March 31, 2013. 
8. Charach A, Yeung E, Climans T, Lillie E. Childhood attentiondeficit/hyperactivity disorder and future substance use disorders: comparative meta-analyses. J Am Acad Child Adolesc Psychiatry. 2011;50(1):9-21.

9. Bachmann K, Lam A, Philipsen A. Mindfulness-based cognitive therapy and the adult ADHD brain: a neuropsychotherapeutic perspective. Frontiers in Psychiatry. 2016;7(117):1-7.

10. Paclt I, Ptácek R, Kuzelová H, et al. Circadian rhythms of saliva melatonin in ADHD, anxious and normal children. Neuro Endocrinol Lett. 2011;32(6):790-798.

11. Stefano GB, Ptacek R, Kuzelova H, Kream RM. Endogenous morphine: up-to-date review 2011. Folia Biol (Praha). 2012;58(2):49.

12. Goetz M, Schwabova J, Hlavka Z, et al. Cerebellar symptoms are associated with omission errors and variability of response time in children with ADHD. J Atten Disord. Epub 2014 Jan 10.

13. Shaw P, Eckstrand K, Sharp W, et al. Attention-deficit/hyperactivity disorder is characterized by a delay in cortical maturation. Proc Natl Acad Sci U S A. 2007;104(49):19649-19654.

14. Valera EM, Faraone SV, Murray KE, Seidman LJ. Meta-analysis of structural imaging findings in attention-deficit/hyperactivity disorder. Biol Psychiatry. 2007;61(12):1361-1369.

15. Lou HC. Etiology and pathogenesis of attention-deficit hyperactivity disorder (ADHD): significance of prematurity and perinatal hypoxic-haemodynamic encephalopathy. Acta Paediatr. 1996;85(11): 1266-1271.

16. Oades RD. Dopamine-serotonin interactions in attention-deficit hyperactivity disorder (ADHD). In: Giovanni GD, Matteo VD, Esposito E, editors. Progress in Brain Research. Vol 172. Serotonindopamine interaction: experimental evidence and therapeutic relevance. Amsterdam: Elsevier; 2008:543-565.

17. Paddock C. ADHD cause unlikely to be dopamine dysfunction. $M N T$; 2013 [October 29]. Available from: http://www.medicalnewstoday. com/articles/268016.php. Accessed May 30, 2016.

18. Ptacek R, Kuzelova H, Stefano GB. Genetics in psychiatry up-to-date review 2011. Neuro Endocrinol Lett. 2011;32(4):389.

19. Kuzelova H, Ptacek R, Macek M. The serotonin transporter gene (5-HTT) variant and psychiatric disorders: review of current literature. Neuro Endocrinol Let. 2009;31(1):4-10.

20. Dmitrieva J, Chen C, Greenberger E, Ogunseitan O, Ding YC. Genderspecific expression of the DRD4 gene on adolescent delinquency, anger and thrill seeking. Soc Cogn Affect Neurosci. 2011;6(1):82-89.

21. Ptacek R, Kuzelova H, Paclt I, Zukov I, Fischer S. ADHD and growth: anthropometric changes in medicated and non-medicated ADHD boys. Med Sci Monit. 2009;15(12):CR595-CR599.

22. Ptacek R, Kuzelova H, Stefano GB, et al. Disruptive patterns of eating behaviors and associated lifestyles in males with ADHD. Med Sci Monit. 2014;20:608.

23. Bralten J, Franke B, Waldman I, et al. Candidate genetic pathways for attention-deficit/hyperactivity disorder (ADHD) show association to hyperactive/impulsive symptoms in children with ADHD. J Am Acad Child Adolesc Psychiatry. 2013;52(11):1204.e1-1212.e1.

24. Grizenko N, Paci M, Joober R. Is the inattentive subtype of ADHD different from the combined/hyperactive subtype? J Atten Disord. 2010; 13(6):649-657.

25. Halfon N, Larson K, Slusser W. Associations between obesity and comorbid mental health, developmental, and physical health conditions in a nationally representative sample of US children aged 10 to 17. Acad Pediatr. 2013;13(1):6-13.

26. Nigg JT. Attention-deficit/hyperactivity disorder and adverse health outcomes. Clin Psychol Rev. 2013;33(2):215-228.

27. Kuzelova H, Macek M, Raboch J, Ptacek R. Genetická variabilita u poruchy pozornosti s hyperaktivitou (ADHD). [Genetic variability in ADHD Hyperactive Subtype]. Cesk Neurol Neurochir. 2014;77(4):423427. Slovak.

28. Cortese S, Comencini E, Vincenzi B, Speranza M, Angriman M. Attention-deficit/hyperactivity disorder and impairment in executive functions: a barrier to weight loss in individuals with obesity? $B M C$ Psychiatry. 2013;13:286.
29. Wilens T, Zulauf C. Attention-deficit/hyperactivity disorder and substance use disorders. In: Yifrah Kaminer, editor. Youth substance abuse and co-occurring disorders. Arlington: American Psychiatric Publishing, Inc.; 2016:103-129.

30. Roll J, Saules K, Chudzynski J, Sodano R. Relationship between Tridimensional Personality Questionnaire scores and clinic attendance among cocaine abusing, buprenorphine maintained outpatients. Subst Use Misuse. 2004;39(6):1025-1040.

31. Zimbardo PG, Boyd JN. Putting time in perspective: a valid, reliable individual-differences metric. In: Time Perspective Theory; Review, Research and Application. Switzerland: Springer; 2015:17-55.

32. Ptácek R, Kuzelová H, Stefano GB. Dopamine D4 receptor gene DRD4 and its association with psychiatric disorders. Med Sci Monit. 2011;17(9):RA215-RA220.

33. Kranzler HR, Edenberg HJ. Pharmacogenetics of alcohol and alcohol dependence treatment. Curr Pharm Des. 2010;16(19):2141-2148.

34. Ortuno V, Printsevsky I, Sircova A. Time Perspective predictive power in alcohol consumption behaviors. Presented at: 17th European Congress of Psychology; July 2009.

35. Ostojic D, Charach A, Henderson J, McAuley T, Crosbie J. Childhood ADHD and addictive behaviours in adolescence: A Canadian sample. $J$ Can Acad Child Adolesc Psychiatry. 2014;23(2):128-135.

36. Lee JH. An update on necrotizing enterocolitis: pathogenesis and preventive strategies. Korean J Pediatr. 2011;54(9):368.

37. Groenman AP, Oosterlaan J, Rommelse N, et al. Substance use disorders in adolescents with attention deficit hyperactivity disorder: a 4-year follow-up study. Addiction. 2013;108(8):1503-1511.

38. Woo HD, Kim DW, Hong YS, et al. Dietary patterns in children with attention deficit/hyperactivity disorder (ADHD). Nutrients. 2014;6(4): $1539-1553$

39. Howard AL, Robinson M, Smith GJ, Ambrosini GL, Piek JP, Oddy WH. ADHD is associated with a "Western" dietary pattern in adolescents. J Atten Disord. 2011;15(5):403-411.

40. Sonneville KR, Calzo JP, Horton NJ, et al. Childhood hyperactivity/ inattention and eating disturbances predict binge eating in adolescence. Psychol Med. 2015;45(12):2511-2520.

41. Wilhelm C, Marx I, Konrad K, et al. Differential patterns of disordered eating in subjects with ADHD and overweighta. World J Biol Psychiatry. 2011;12(supp1):118-123.

42. Puhl MD, Cason AM, Wojnicki FH, Corwin RL, Grigson PS. A history of bingeing on fat enhances cocaine seeking and taking. Behav Neurosci. 2011;125(6):930-942.

43. Swanson SA, Crow SJ, Le Grange D, Swendsen J, Merikangas KR. Prevalence and correlates of eating disorders in adolescents. Results from the national comorbidity survey replication adolescent supplement. Arch Gen Psychiatry. 2011;68(7):714-723.

44. Shapira NA, Lessig MC, Goldsmith TD, et al. Problematic internet use: proposed classification and diagnostic criteria. Depress Anxiety. 2003;17(4):207-216.

45. Yau Y, Derevensky J, Potenza M. Pathological preoccupation with the Internet. In: Youth Substance Abuse and Co-Occurring Disorders [e-book]. Arlington, VA, US: American Psychiatric Publishing, Inc.; 2016:337-349.

46. Wartberg L, Brunner R, Kaess M, et al. Psychopathological factors associated with problematic alcohol and problematic internet use in a sample of adolescents in Germany. Psychiatry Res. 2016;240:272-277.

47. Finlay F, Furnell C. G355 internet addiction disorder/problematic internet use and ADHD. Arch Dis Child. 2014;99(Suppl 1):A145-A146.

48. Zimbardo PG, Coloumbe N. Man (Dis)connected: Why Men are Struggling and How Can They Be Helped. San Francisco: Jossey-Bass Publishing; 2015.

49. Hyun GJ, Han DH, Lee YS, et al. Risk factors associated with online game addiction: a hierarchical model. Comput Hum Behav. 2015;48: 706-713.

50. Dalbudak E, Evren C, Aldemir S, Taymur I, Evren B, Topcu M. The impact of sensation seeking on the relationship between attention deficit/hyperactivity symptoms and severity of Internet addiction risk. Psychiatry Res. 2015;228(1):156-161. 
51. Ha Y-M, Hwang WJ. Gender differences in internet addiction associated with psychological health indicators among adolescents using a national web-based survey. Int J Ment Health Addiction. 2014;12(5):660-669.

52. Zhang Q, Wang Y, Yuan C, Zhang X, Li Y. The gender effect on the relationship between internet addiction and emotional and behavioral problems in adolescents. Chin J Clin Psychol. 2014;22(6): 1004-1009.

53. Lingineni RK, Biswas S, Ahmad N, Jackson BE, Bae S, Singh KP. Factors associated with attention deficit/hyperactivity disorder among US children: results from a national survey. BMC Pediatr. 2012;12:50.

54. Johnston C. Parent characteristics and parent-child interactions in families of nonproblem children and ADHD children with higher and lower levels of oppositional-defiant behavior. J Abnorm Child Psychol. 1996;24(1):85-104.

55. Musser ED, Karalunas SL, Dieckmann N, Peris TS, Nigg JT. Attention-deficit/hyperactivity disorder developmental trajectories related to parental expressed emotion. J Abnorm Psychol. 2016;125(2): 182-195.

56. Calafat A, García F, Juan M, Becoña E, Fernández-Hermida JR. Which parenting style is more protective against adolescent substance use? Evidence within the European context. Drug Alcohol Depend. 2014;138: 185-192.

57. Worrell FC, McKay MT, Andretta JR. Concurrent validity of Zimbardo time perspective inventory profiles: a secondary analysis of data from the United Kingdom. J Adolesc. 2015;42:128-139.

58. Timpano KR, Carbonella JY, Keough ME, Abramowitz J, Schmidt NB. Anxiety sensitivity: an examination of the relationship with authoritarian, authoritative, and permissive parental styles. J Cogn Psychother. 2015;29(2):95-105.

59. Iglesias EB, Fernández del Río E, Calafat A, Fernández-Hermida JR. Attachment and substance use in adolescence: A review of conceptual and methodological aspects. Adicciones. 2014;26(1):76-86.

60. Wilens TE. AOD use and attention deficit/hyperactivity disorder. Alcohol Health Res World. 1998;22(2):127-130.

61. Krone B, Newcorn J. Comorbidity of ADHD and anxiety disorders: Diagnosis and treatment across the lifespan. In: Adler LA, Spencer TJ, Wilens TE, editors. Attention-deficit hyperactivity disorder in adults and children. New York: Cambridge University Press; 2015:98-110.

62. Tancred E-M, Greeff AP. Mothers' parenting styles and the association with family coping strategies and family adaptation in families of children with ADHD. Clin Soc Work J. 2015;43(4):442-451.

63. Stolarski M, Zajenkowski M, Zajenkowska A. Aggressive? from time to time ... uncovering the complex associations between time perspectives and aggression. Curr Psychol. 2016;35:1-10.

64. Bubenzer-Busch S, Herpertz-Dahlmann B, Kuzmanovic B, et al. Neural correlates of reactive aggression in children with attention-deficit/ hyperactivity disorder and comorbid disruptive behaviour disorders. Acta Psychiatr Scand. 2016;133(4):310-323.
65. Keough KA, Zimbardo PG, Boyd JN. Who's smoking, drinking, and using drugs? time perspective as a predictor of substance use. Basic Appl Soc Psych. 1999;21(2):149-164.

66. Polanczyk G, de Lima MS, Horta BL, Biederman J, Rohde LA. The worldwide prevalence of ADHD: a systematic review and metaregression analysis. Am J Psychiatry. 2007;164(6):942-948.

67. Shifflett PA. Future time perspective, past experiences, and negotiation of food use patterns among the aged. Gerontologist. 1987;27(5): 611-615.

68. Fuchs T, Kurz A, Lauter H. The importance of the personal past, present, and future in the treatment of depressed elderly patients. Nervenarzt. 1991;62(5):313-317.

69. Bitsko MJ, Stern M, Dillon R, Russell EC, Laver J. Happiness and time perspective as potential mediators of quality of life and depression in adolescent cancer. Pediatr Blood Cancer. 2008;50(3):613-619.

70. Gruber J, Cunningham WA, Kirkland T, Hay AC. Feeling stuck in the present? Mania proneness and history associated with present-oriented time perspective. Emotion. 2012;12(1):13-17.

71. Beiser M. Changing time perspective and mental health among Southeast Asian refugees. Cult Med Psychiatry. 1987;11(4):437-464.

72. Beiser M, Hyman I. Refugees' time perspective and mental health. Am J Psychiatry. 1997;154(7):996-1002.

73. Black WAM, Gregson RAM. Time perspective, purpose in life, extraversion and neuroticism in New Zealand prisoners. Br J Soc Clin Psychol. 1973;12(1):50-60.

74. Henik W, Domino G. Alterations in future time perspective in heroin addicts. J Clin Psychol. 1975;31(3):557-564.

75. Hodgins DC, Engel A. Future time perspective in pathological gamblers. J Nerv Ment Dis. 2002;190(11):775-780.

76. Lukavska K. Time perspective as a predictor of massive multiplayer online role-playing game playing. Cyberpsychol Behav Soc Netw. 2011 15(1):50-54.

77. Flora SR. Taking America Off Drugs: Why Behavioral Therapy Is More Effective for Treating ADHD, OCD, Depression, and Other Psychological Problems. New York: SUNY Press; 2012.

78. Carelli MG, Wiberg B. Time out of mind: temporal perspective in adults with ADHD. J Atten Disord. 2012;16(6):460-466.

79. James W. The Principles of Psychology Consciousness in the Physical World: Perspectives on Russellian Monism [e-book]. New York, NY, US: Oxford University Press; 2015:23-26.

80. Klicperová-Baker M, Košt'ál J, Vinopal J. Time perspective in consumer behavior. In: Time Perspective Theory; Review, Research and Application. Switzerland: Springer; 2015:353-369.
Neuropsychiatric Disease and Treatment

\section{Publish your work in this journal}

Neuropsychiatric Disease and Treatment is an international, peerreviewed journal of clinical therapeutics and pharmacology focusing on concise rapid reporting of clinical or pre-clinical studies on a range of neuropsychiatric and neurological disorders. This journa is indexed on PubMed Central, the 'PsycINFO' database and CAS,

\section{Dovepress}

and is the official journal of The International Neuropsychiatric Association (INA). The manuscript management system is completely online and includes a very quick and fair peer-review system, which is all easy to use. Visit http://www.dovepress.com/testimonials.php to read real quotes from published authors. 